\title{
A Survey among Texas Pain Society Physicians Regarding the Types and Dosages of Steroids Utilized Clinically in Epidural Steroid Injectates
}

\author{
Thuan Dao*, Ioannis Skaribas \\ Department of Anesthesiology, University of Texas Medical School at Houston, Houston, USA \\ Email: ${ }^{*}$ thuan.d.dao@uth.tmc.edu
}

Received 20 September 2014; revised 21 October 2014; accepted 25 November 2014

Copyright (C) 2014 by authors and Scientific Research Publishing Inc.

This work is licensed under the Creative Commons Attribution International License (CC BY). http://creativecommons.org/licenses/by/4.0/

(c) (i) Open Access

\section{Abstract}

Objective: Epidural steroid injections (ESI) are used extensively to treat radicular back pain. This study is designed to evaluate the types and dosages of steroids commonly used and understand prescribing habits of the Texas Pain Society pain management physicians. Method: From April to May 2014, we sent all 270 Texas Pain Society members a questionnaire to complete online. We collected 45 responses. Result: Type of steroid commonly used in injectate: Eighteen $(41.9 \%)$ physicians reported using methylprednisolone most. Fifteen $(34.9 \%)$ physicians use triamcinolone, 9 $(20.9 \%)$ physicians use dexamethasone, $1(2.3 \%)$ uses betamethasone, and 2 skipped this question. Important factors influencing the type of steroid use in injectate: Half of the physicians reported that the location of the ESI was most important (19 responses, $48.7 \%)$. Ten $(25.6 \%)$ reported that the approach of the ESI was most important. Another ten (25.6\%) agreed that the potency of the steroid was most important. Dosage of steroid used in injectate: About half of the physicians use a fixed dose of steroid $(22,51.2 \%)$ while $21(48.8 \%)$ use a variable dose of steroid. Of those who use a fixed dose of steroid, many use methylprednisolone $80 \mathrm{mg}(9,39.1 \%)$. Of those who use a variable dosage of steroid, the most important factor in their determination of the dosage is the patient's comorbidities ( 20 responses, $58.8 \%$ ). The use of depo-steroid in injectate: Thirty-two out of $43(74.4 \%)$ use depo-steroid while 11 out of $43(25.6 \%)$ wouldn't use depo-steroid. Of those who use depo-steroid, the duration and availability in the epidural space is the most common reason for its use $(23,76.7 \%)$. Conclusion: By using a simple questionnaire detailing what types and dosages of steroids are used, compiling a list of best practices can help Texas Pain Society physicians tremendously in the treatment of radicular back pain.

\footnotetext{
${ }^{*}$ Corresponding author.
}

How to cite this paper: Dao, T. and Skaribas, I. (2014) A Survey among Texas Pain Society Physicians Regarding the Types and Dosages of Steroids Utilized Clinically in Epidural Steroid Injectates. Open Journal of Anesthesiology, 4, 291-299. 


\section{Keywords}

\section{Epidural Steroid Injection, Radicular Back Pain, Type of Steroid, Dosage of Steroid, Injectate, Methylprednisolone, Triamcinolone, Dexamethasone, Betamethasone}

\section{Introduction}

Chronic radicular back pain is a common health problem that debilitated millions of people in the United States annually [1] [2]. In 1977, it was first postulated that when an intact disc was injured, phospholipase A2 (PLA2) was released, causing an inflammatory cascade involving the liberation of arachidonic acid, leukotrienes, and prostaglandins [3]. These inflammatory mediators increase vascular permeability of the endoneural blood vessels, causing edema and pain [4]. Currently, conservative managements for radicular back pain begin with exercise, weight loss, and physical therapy. When conservative measures fail, however, epidural steroid injections are the next step in management for these patients [2]. Epidural steroid works by reducing inflammation through maintaining membrane stability, inhibiting neuropeptide synthesis, blocking PLA2, and stopping C-fiber conduction responsible for pain sensation [2] [4]-[7]. The rationale for epidural steroid injections is not to cure anatomic abnormalities but to improve symptoms so patients can participate in rehabilitation, allowing a timely return to a normal lifestyle with maximum function [2] [5] [8].

Currently, the most commonly used preparations of steroid for neuraxial blockage are betamethasone acetate, dexamethasone, triamcinolone acetonide and diacetate, and methylprednisolone acetate [9]. There is no consensus among physicians on which types or dosages of steroids to use in the clinical setting. The objective of this study is to evaluate the types and dosages of steroids commonly used and understand the rationale behind the prescribing habits of the chronic pain management physicians in Texas.

\section{Method}

This study did not require approval from our internal review board. With the approval of the Texas Pain Society, 270 contacts were released to the principle investigator. At the beginning of April 2014, an email was sent to all Texas Pain Society members detailing the purpose of the study and inviting each member to complete a questionnaire through an interactive link (Appendix). Every two weeks since April 2014, an email was sent out to remind members to complete the online survey until the end of May 2014. The names and responses of the physicians were kept confidential and no incentives were given for their participation in the survey.

\section{Result}

After the two-month survey period, we collected 45 out of 270 surveys (16.6 \%). Of the 45 surveys received, 34 responses were from anesthesia trained pain physicians (79.1\%), 8 responses were from PMNR (physical medicine and rehab) trained physicians (18.6\%), 1 response (2.3\%) was from a neurology trained pain physician, 1 response (2.3\%) was from a family medicine trained pain physician, and 1 response was from a physician who chose not to answer this question.

\subsection{Type of Steroid Commonly Used in Injectate}

Of the 45 surveys received, 18 (41.9\%) physicians reported that they use methylprednisolone most in their injectate. Fifteen (34.9\%) physicians use triamcinolone, 9 (20.9\%) use dexamethasone, 1 (2.3\%) uses betamethasone, and 2 physicians did not comment on the most common type of steroid used in their injectate, stating that the type of steroid used depends on the location of the epidural steroid injection (Figure 1).

\subsection{Important Factors Influencing the Type of Steroid Used in Injectate}

Almost half of the physicians in the survey reported that the most important factor guiding their selection of steroid in their injectate is the location of the epidural steroid injection (19 responses, 48.7\%). Ten (25.6\%) physicians stated that the most important factors in determining the type of steroid used is the approach of the epi- 
dural steroid injection (interlaminar vs. caudal vs. transforaminal). Another ten (25.6\%) physicians agreed that the most important factor is the potency of the steroid (Figure 2). Six physicians skipped this question, com-

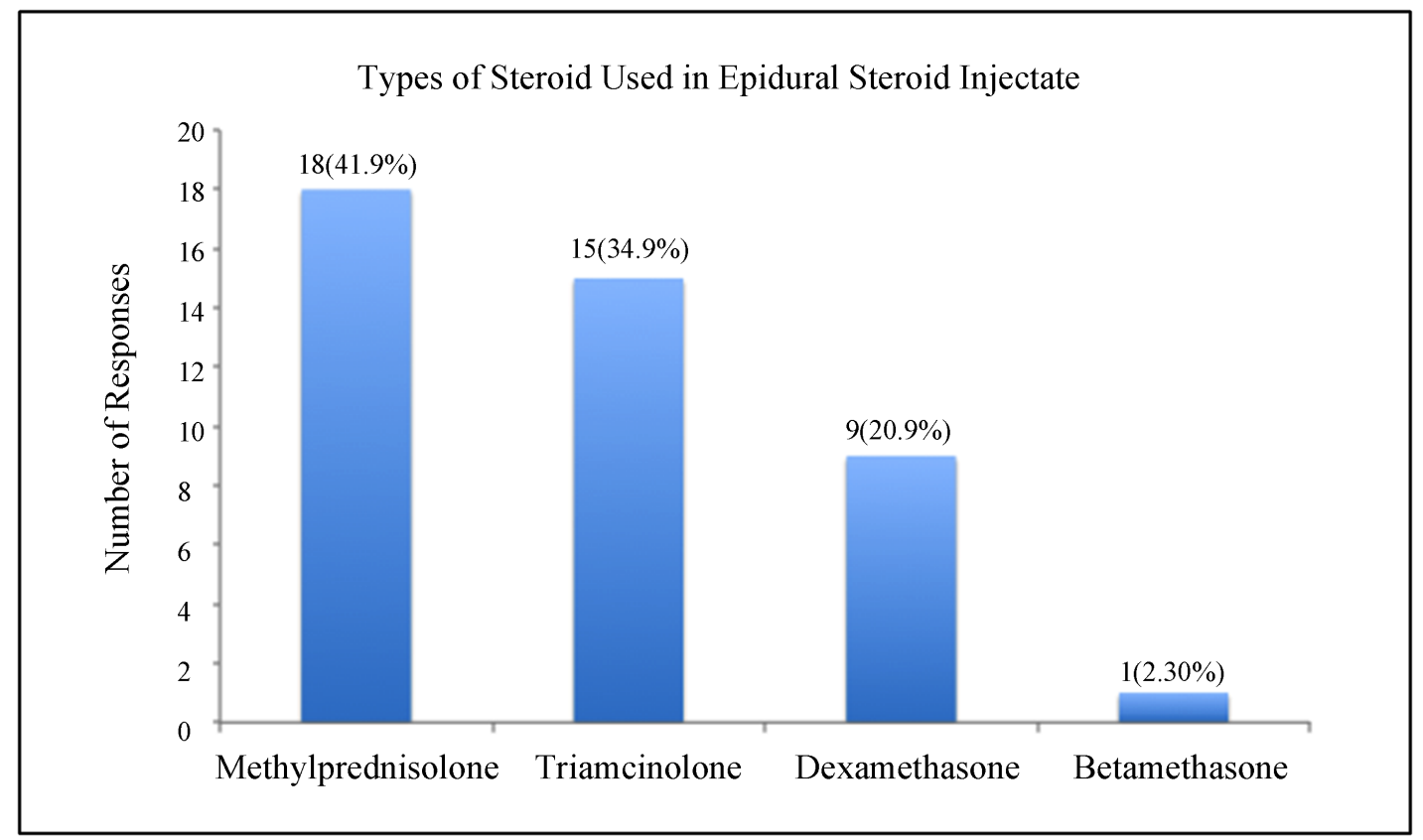

Figure 1. Types of steroid used in injectate. Eighteen (41.9\%) physicians reported that they use methylprednisolone most in their injectate. Fifteen (34.9\%) physicians use triamcinolone, 9 (20.9\%) use dexamethasone, 1 (2.3\%) uses betamethasone, and 2 physicians did not comment on the type of steroid used in their injectate.

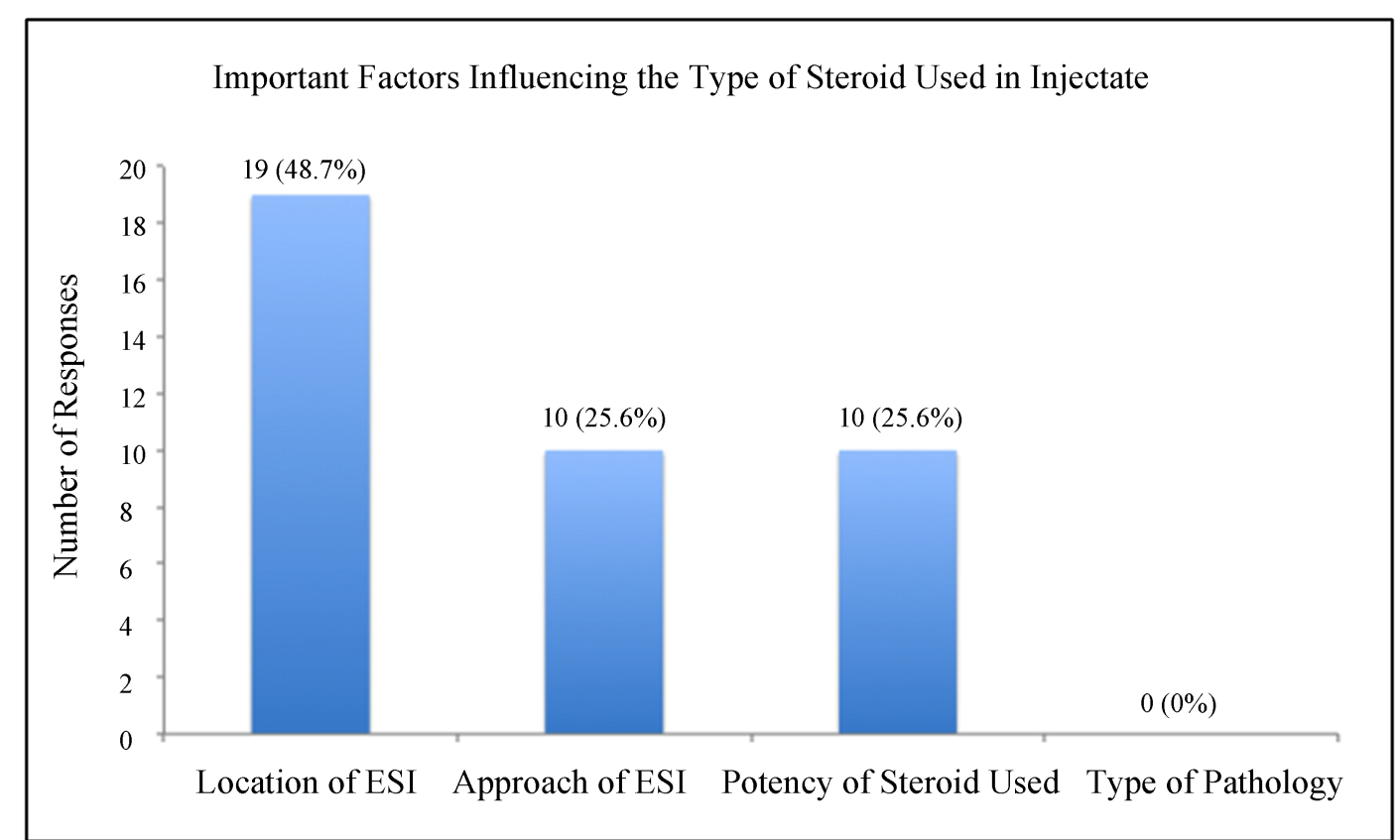

Figure 2. Important factors influencing the type of steroid in injectate. Nineteen physicians (48.7\%) reported that the most important factor guiding their selection of steroid in their injectate is the location of the epidural steroid injection. Ten (25.6\%) physicians stated that the most important factor is the approach of the epidural steroid injection (interlaminar vs. caudal vs. transforaminal). Another ten (25.6\%) physicians agreed that the most important factor is the potency of the steroid. Six physicians skipped this question, commenting on reasons such as formulary, absorption, and non-particulate preparations of the steroid as being the most important factor in their selection of steroid used in their practice. 
menting on reasons such as formulary, absorption, and non-particulate preparations of the steroid as being the most important factor in their selection of the steroid used in their practice.

\subsection{Dosage of Steroid Used in Injectate}

About half of the physicians in the survey use a fixed dose of steroid (22 responses, $51.2 \%$ ) while 21 physicians (48.8\%) use a variable dose of steroid in their practice. Of those who use a fixed dose of steroid, many use methylprednisolone $80 \mathrm{mg}$ in their injectate (9 responses, 39.1\%). The second most common type and dosage of steroid used is dexamethasone $10 \mathrm{mg}$ (4 responses, 17.4\%) (Figure 3). Of the physicians who use a variable dosage of steroid, the most important determination in their selection of the dosage is the patient's comorbidities such as diabetes, adrenal insufficiency, etc. (20 responses, 58.8\%). Seven physicians (20.6\%) commented that the most important factor in their selection of the dosage of steroid is the location of the epidural steroid injection (Figure 4).

\subsection{The Use of Depo-Steroid (Particulate Steroid) in Injectate}

Of the 45 surveys collected, 2 physicians did not comment on the use of depo-steroid in their practice. Thirty-two out of 43 physicians (74.4\%) stated that they use depo-steroid while 11 out of 43 (25.6\%) would not use depo-steroid. Of those who use depo-steroid, the duration and availability of the depo-steroid is the most common reason for its use (23 physicians, 76.7\%). Ten percent of physicians use depo-steroid because of its potency and another 10 percent use depo-steroid due to its safety. On the other hand, only one physician stated that the cost and market availability of depo-steroid is the reason for its use in his/her clinical practice.

\subsection{The Use of Compound Steroid in Injectate}

One out of 45 physicians did not comment on the use of compound steroid. However, of the 44 physicians, 38 (86.36\%) stated that they would not use compound steroid in their practice. Of the six physicians who use compound steroid, 4 (66.67\%) stated that the cost and availability of this steroid preparation is the main reason for

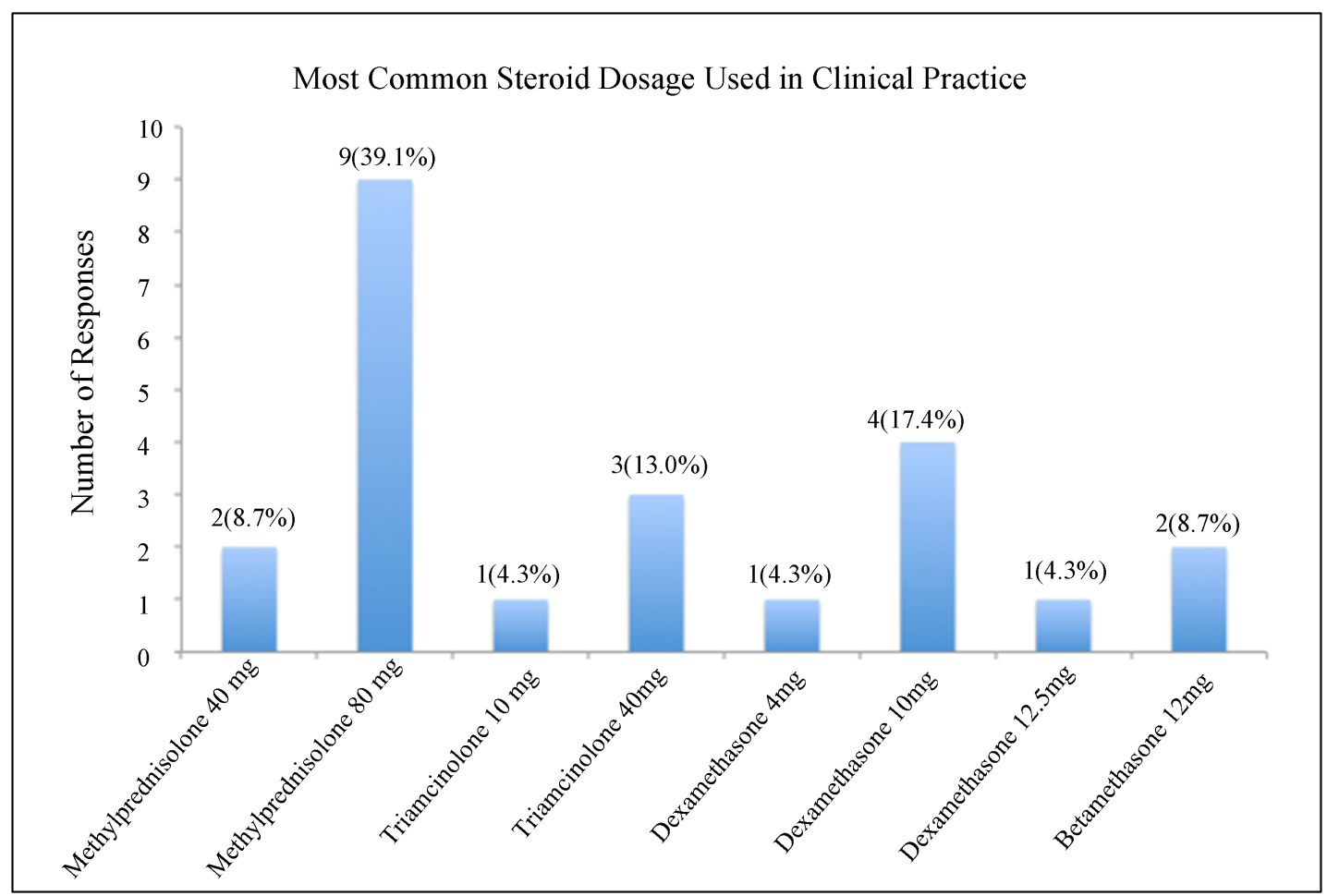

Figure 3. Most common steroid dosage used in clinical practice. Twenty-three physicians skipped this question, stating that they use a variable dose of steroid. 


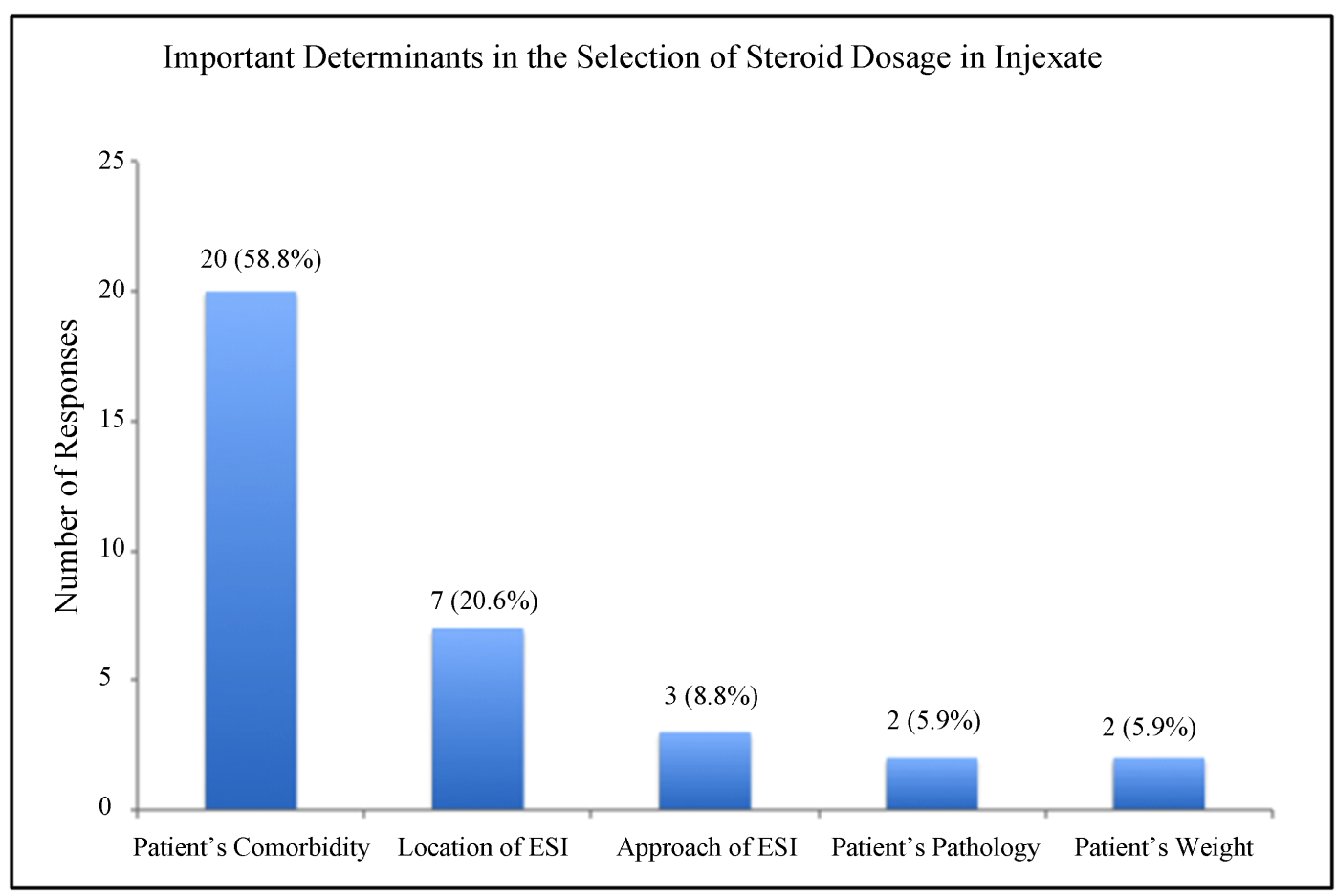

Figure 4. Important determinants in the selection of steroid dosage in clinical practice. Eleven physicians skipped this question.

its use. One physician noted that the reason for its use is its duration and availability in the epidural space while another stated that the safety profile is the reason for its use in the clinic. Interestingly, one physician stated that she/he used compound steroid in the past but stopped after the outbreak of fungal meningitis among patients who received contaminated steroid injections manufactured from the New England Compounding Center in Framingham, Massachusetts in 2012.

\section{Discussion}

Even though there are a few types of steroid available, it is challenging for physicians to select the most appropriate steroid in their clinical practice. Furthermore, the Food and Drug Administration has not approved the use of some steroids such as triamcinolone and betamethasone for epidural injections [1]. Although some physicians may prefer to use one steroid over another, many studies are equivocal when comparing the efficacy between steroids. In 2003, Stanczak et al. compared the efficacy of triamcinolone versus betamethasone in 597 patients. There were 278 injections of betamethasone and 319 injections of triamcinolone, and patients were instructed to rank their pain using an 11-point scale $(0=$ no pain, $10=$ maximum pain) during initial visit, 1 day after the procedure, 3 days after the procedure, 7 days after the procedure, and 14 days after the procedure. They consistently found triamcinolone to be superior to betamethasone. Furthermore, the triamcinolone group reported that less pain medication was needed after 14 days post procedure [1]. It is postulated that triamcinolone may form crystalline deposits, which act as a better reservoir for medication and thus has a more prolonged effect than betamethasone. However, a study that analyzed the most commonly used corticosteroids found that betamethasone particles varied greatly in size, were densely packed, and formed extensive aggregations very similarly to triamcinolone [6].

In 2005, Blankenbaker et al. from the same institution undertook a study to determine if their result would support that of Stanczak and colleagues. One hundred thirty injections were performed with either triamcinolone (49 patients) or betamethasone (81 patients) and patients were instructed to rank their pain using an 11-point scale ( $0=$ no pain, $10=$ maximum pain) during initial visit, 1 day after the procedure, 3 days after the procedure, 7 days after the procedure, and 14 days after the procedure. In contrast, they found that there is no statistical difference between the triamcinolone and the betamethasone group [2]. 
Similarly, a few comparative studies since 2005 found no difference in efficacy between selected steroids when used in the epidural space. In 2011, a study that compared dexamethasone and methylprednisolone in the treatment of lumbar radiculopathy by lumbar epidural injection found that both are equivalent in efficacy and adverse effects [10]. In 2014, Kennedy et al. designed a multicenter, double blind, prospective, randomized trial on 78 patients with disc herniation resulting in unilateral radicular pain using dexamethasone or triamcinolone. The study found that both dexamethasone and triamcinolone resulted in improvements in pain and function at 2 weeks, 3 months, and 6 months, without differences between the groups [11]. In our survey, many physicians commonly use methylprednisolone in their injectate perhaps because even though it may form aggregate, the chance of an embolic event is less than triamcinolone and betamethasone because its aggregates are generally smaller than a red blood cell [6].

Epidural steroid injections carry a few notable risks, with vasovagal reaction as the most common adverse reaction during the procedure. After the procedure, the most common side effects are nausea, facial flushing, fever, insomnia, non-positional headache, and transient increase in pain [3]. Serious side effects include arachnoiditis, epidural abscess, bacterial meningitis, intrathecal injection, and particulate embolism [9] [12]. Cervical epidural steroid injections carry higher risks than epidural steroid injections at the lumbar levels, as damage to the spinal cord at the cervical level can cause respiratory distress, a risk that is essentially absent in the lumbar area. Because of the different side effect profiles of each corticosteroid, it is understandable that almost half of our survey physicians agreed that the most important factor guiding their selection of steroid is the location of the epidural steroid injection (19 responses, 48.7\%). Ten (25.6\%) physicians stated that the most important factor is the approach of the epidural steroid injection (interlaminar vs. caudal vs. transforaminal). In 2010, Colimon et al. reported several serious events related to the use of depo-steroids in the cervical epidural space via the transforaminal approach [6]. The explanation for this is an occlusion of the segmental artery by the steroid particulate. The ascending and deep cervical arteries are within $2 \mathrm{~mm}$ of the path of the needle during the transforaminal approach and these two arteries with the vertebral artery supply the segmental medullary vessels for the spinal cord [9].

Interestingly, about half of physicians use a fixed dose of steroid (22 responses, $51.2 \%$ ) while 21 physicians (48.8\%) use a variable dose of steroid. Of those who use a fixed dose of steroid in their injectate, many use methylprednisolone $80 \mathrm{mg}$ (9 responses, 39.1\%). Perhaps the reason for the use of this high dose of steroid is the relatively healthy patient population these physicians see in their clinic, and thus side effects are mitigated. Furthermore, if there is a depression of the hypothalamus pituitary adrenal axis, it is expected to return to normal at 35 days after the procedure in high dose as well as low dose corticosteroid [9].

On the other hand, of the physicians who use a variable dosage of steroids, the most important factor in their selection of the dosage is the patient's comorbidities such as diabetes, adrenal insufficiency, etc. (20 responses, $58.8 \%)$. High dosage of corticosteroids can be accompanied by adverse metabolic systemic side effects, such as hyperglycemia, especially in diabetic patients. In a prospective randomized study in 84 patients with radicular lower back pain, methylprednisolone $80 \mathrm{mg}$ and methylprednisolone $40 \mathrm{mg}$ showed similar analgesic results and a greater tendency toward hyperglycemia in the group with the higher dosage of steroid. Thus, in diabetic patients, lowering the total dose of steroids in the epidural space is recommended [6]. Seven physicians (20.6\%) commented that the most important factor in their selection of the dosage of steroid is the location of the epidural steroid injection. The epidural space in an adult measures about $0.4 \mathrm{~mm}$ at C7-T1, $7.5 \mathrm{~mm}$ at the upper thoracic regions, $4.1 \mathrm{~mm}$ at the T11-12 region and $4-7 \mathrm{~mm}$ at the lumbar regions. Due to the variable size of the epidural space, it is reasonable for a significant variation in volumes as well as dosages used for the cervical, thoracic, lumbar, and caudal epidural injections.

Of the 45 responses, two did not comment on the use of depo-steroid. Thirty-two out of 43 physicians (74.4\%) stated that they use depo-steroid while 11 out of 43 (25.6\%) would not use depo-steroid in their practice. Of those who use depo-steroid, the duration and availability of the depo-steroid is the most common reason for its use (23 physicians, 76.7\%). Depo-steroid has the ability to form crystalline deposits, which serve as a reservoir for medication, theoretically prolonging their effect [1]. Of the four most commonly used corticosteroids, triamcinolone and betamethasone particles tend to coalesce into large aggregates. Methylprednisolone may also form crystalline deposits, but their crystals are much smaller than a red blood cell. On the other hand, particles of dexamethasone are rod-like, lucent, and purely liquid soluble [9]. Although many physicians use depo-steroid, many studies are equivocal when comparing their efficacy with non-particulate steroids. However, it is worth mentioning that many of these studies only analyzed a limited number of patients in a short period of time after 
the epidural steroid injection.

Finally, 38 out of 44 physicians (86.36\%) stated that they would not use compound steroid in their practice. Of the six physicians who use compound steroid, 4 (66.67\%) stated that the cost and availability is the main reason for its use. Costs and availability of medications is an important aspect of patient care that pain specialists deal with everyday. It is understandable, from an economic perspective, how the cost and availability of medications can influence the prescribing habits of the physicians. However, 38 out of 44 physicians would not use compound steroids in their practice perhaps due to the historical outbreak of meningitis in the New England area. In September 2012, the Food and Drug Administration investigated 751 cases of fungal meningitis and localized spinal or paraspinal infections in 20 states with 64 deaths associated with compounded steroids. Even though there are only 2 cases reported in Texas, many Texas pain physicians are hesitant about the use of compound steroids and would prefer brand name steroids.

To our knowledge, this survey is the first of its kind to circulate through the Texas Pain Society. This pilot study focuses on the simplicity of the method, and we expect future modification and replication of this questionnaire to circulate through different pain management organizations. Free-text answers are embedded in the surveys so physicians can response openly about their experience when answering each question. The open-ended answers are reported in the results and incorporated in the figures. We should note that we only received 45 responses from 270 surveys. However, it is worth mentioning that not all Texas Pain Society members are physicians and not all physicians participate in epidural steroid injections. In the future, we will revise this survey and only send to physicians who participate in epidural steroid injections. This will give us a better response rate and allow a simple statistical analysis to make the result even more informative.

\section{Conclusion}

Even though epidural steroid injections have been used extensively for the treatment of radicular back pain, there is no gold standard for epidural steroid injections. Currently, the protocols for epidural steroid injections vary greatly with regard to the types and dosages of steroids. Future studies need to be undertaken to implement a protocol for the use of steroids in epidural injections. However, a multicenter, randomized, double blind trial is very difficult for interventional therapies. It is more feasible that as the Texas Pain Society membership expands, a statewide registry can easily be instituted. By using a simple questionnaire detailing what types and dosages of steroids are used and what outcomes are achieved, compiling a list of best practices can help Texas pain physicians tremendously in the challenging yet rewarding treatment of radicular back pain.

\section{References}

[1] Stanczak, J., Blankenbaker, D.G., De Smet, A.A. and Fine, J. (2003) Efficacy of Epidural Injections of Kenalog and Celestone in the Treatment of Lower Back Pain. American Journal of Roentgenology, 181, 1255-1258. http://dx.doi.org/10.2214/ajr.181.5.1811255

[2] Blankenbaker, D.G., De Smet, A.A., Stanczak, J. and Fine, J. (2005) Lumbar Radiculopathy: Treatment with Selective Lumbar Nerve Blocks-Comparisons of Effectiveness of Triamcinolone and Betamethasone Injectable Suspensions. Radiology, 237, 738-741. http://dx.doi.org/10.1148/radiol.2372041406

[3] Weinstein, S.M. and Herring, S.A. (2003) Lumbar Epidural Steroid Injections. The Spine Journal, 3, 37-44. http://dx.doi.org/10.1016/S1529-9430(02)00560-0

[4] Koes, B.W., Scholten, R.J.P.M., Jens, J.M.A. and Bouter, L.M. (1995) Efficacy of Epidural Steroid Injections for LowBack Pain and Sciatica: A Systemic Review of Randomized Clinical Trials. Pain, 63, 279-288. http://dx.doi.org/10.1016/0304-3959(95)00124-7

[5] DePalma, M.J. and Slipman, C.W. (2008) Evidence-Informed Management of Chronic Low Back Pain with Epidural Steroid Injections. The Spine Journal, 8, 45-55. http://dx.doi.org/10.1016/j.spinee.2007.09.009

[6] Colimon, F.J. and Villalobos, F.J. (2010) Epidural Steroid Injections: Evidence and Technical Aspects. Techniques in Regional Anesthesia and Pain Management, 14, 113-119. http://dx.doi.org/10.1053/j.trap.2010.06.001

[7] McLain, R.F., Kapural, L. and Mekhail, N.A. (2005) Epidural Steroid Therapy for Back and Leg Pain: Mechanisms of Action and Efficacy. The Spine Journal, 5, 191-201. http://dx.doi.org/10.1016/j.spinee.2004.10.046

[8] Hession, W.G., Stanczak, J.D., Davis, K.W. and Choi, J.J. (2004) Epidural Steroid Injections. Seminars in Roentgenology, 39, 7-23. http://dx.doi.org/10.1016/j.ro.2003.10.010

[9] Kushnerik, V., Altman, G. and Gozenput, P. (2009) Pharmacology of Steroids Used during Epidural Steroid Injections. 
Techniques in Regional Anesthesia and Pain Management, 13, 212-216. http://dx.doi.org/10.1053/j.trap.2009.07.004

[10] Kim, D. and Brown, J. (2011) Efficacy and Safety of Lumbar Epidural Dexamethasone versus Methylprednisolone in the Treatment of Lumbar Radiculopathy: A Comparison of Soluble versus Particulate Steroids. The Clinical Journal of Pain, 27, 518-522. http://dx.doi.org/10.1097/AJP.0b013e31820c53e0

[11] Kennedy, D.J., Plastaras, C., Casey, E., Visco, C.J., Rittenberg, J.D., Conrad, B., Sigler, J. and Dreyfuss, P. (2014) Comparative Effectiveness of Lumbar Transforaminal Epidural Steroid Injections with Particulate versus Nonparticulate Corticosteroids for Lumbar Radicular Pain Due to Intervertebral Disc Herniation: A Prospective, Randomized, Double-Bind Trial. Pain Medicine, 15, 548-555. http://dx.doi.org/10.1111/pme.12325

[12] Valat, J.P. and Rozenberg, S. (2008) Local Corticosteroid Injections for Low Back Pain and Sciatica. Joint Bone Spine, 75, 403-407. 


\title{
Appendix: Texas Pain Society Epidural Steroid Injection Questionnaire
}

\author{
Texas Pain Society \\ Epidural Steroid Injection Questionnaire
}

1. The most common pain management procedure is an epidural steroid injection.

What type of steroid do you usually use in your injectate for an epidural steroid injection?

A. methylprednisolone

B. triamcinolone

C. dexamethasone

D. betamethasone

2. What is most important to you in determining the type of steroid you usually use in your injectate?

A. the location of the epidural steroid injection (cervical vs, thoracic vs. lumbar)

B. the approach of the epidural injection (interlaminar vs. transforaminal)

C. the potency of the steroid

D. the type of pathology the patient has

E. other (please specify):

3. Do you use a fixed dose of steroid?

A. yes

B. no

4. If you use a fixed dose, what steroid and dosage do you usually use for an interlaminar epidural steroid injection?

A. methylprednisolone $40 \mathrm{mg}$

B. methylprednisolone $80 \mathrm{mg}$

C. triamcinolone $10 \mathrm{mg}$

D. triamcinolone $40 \mathrm{mg}$

E. dexamethasone $4 \mathrm{mg}$

F. dexamethasone $10 \mathrm{mg}$

G. dexamethasone $12.5 \mathrm{mg}$

H. betamethasone $12 \mathrm{mg}$

I. other (please specify):

5. If you use a variable dose of steroid, what is most important to you in determining the dose of steroid you usually use in your injectate?

A. the location of the epidural steroid injection (cervical vs. thoracic vs. lumbar)

B. the approach of the epidural injection (interlaminar vs. transforaminal)

C. the type of pathology the patient has (stenosis vs. herniation, etc.)

D. the patient's comorbidity (diabetes, adrenal insufficiency, etc.)

E. other (please specify):

6. Do you use depo-steroid (particulate steroid) in your practice?

A. yes

B. no

7. If you answer "yes" to question 6, why do you prefer to use depo-steroid in your practice?

A. the potency of depo-steroid

B. the duration and availability of depo-steroid in the epidural space

C. the cost of depo-steroid

D. the safety of depo-steroid

E. other (please specify):

8. Do you use compound steroid (as oppose to brand-name steroid) in your practice?

A. yes

B. no

9. If you answer "yes" to question 8, why do you prefer to use compound steroid in your practice?

A. the potency of compound steroid

B. the market availability of the compound steroid

C. the cost of compound steroid

D. the safety of compound steroid

E. other (please specify):

10. What medical specialty most describes you?

A. anesthesia trained pain specialist

B. neurology trained pain specialist

C. internal medicine trained pain specialist

D. psychiatry trained pain specialist

E. PMNR trained pain specialist

F. neurosurgery trained pain specialist

G. other (please specify): 
Scientific Research Publishing (SCIRP) is one of the largest Open Access journal publishers. It is currently publishing more than 200 open access, online, peer-reviewed journals covering a wide range of academic disciplines. SCIRP serves the worldwide academic communities and contributes to the progress and application of science with its publication.

Other selected journals from SCIRP are listed as below. Submit your manuscript to us via either submit@scirp.org or Online Submission Portal.
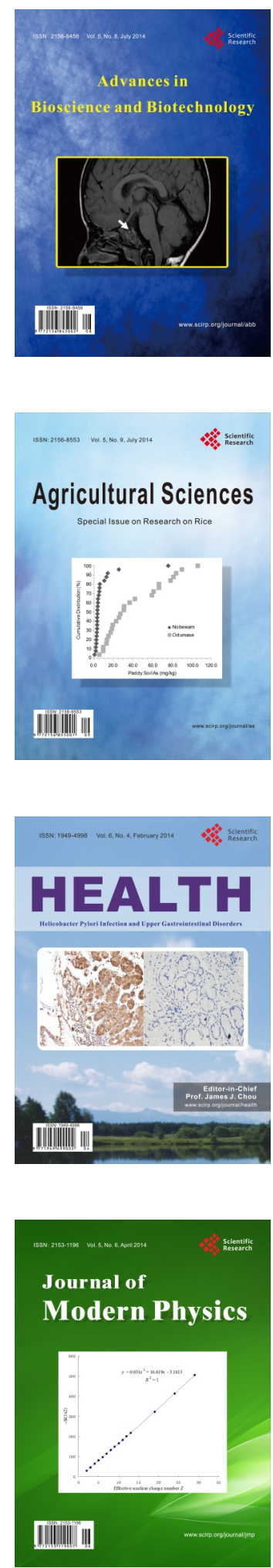
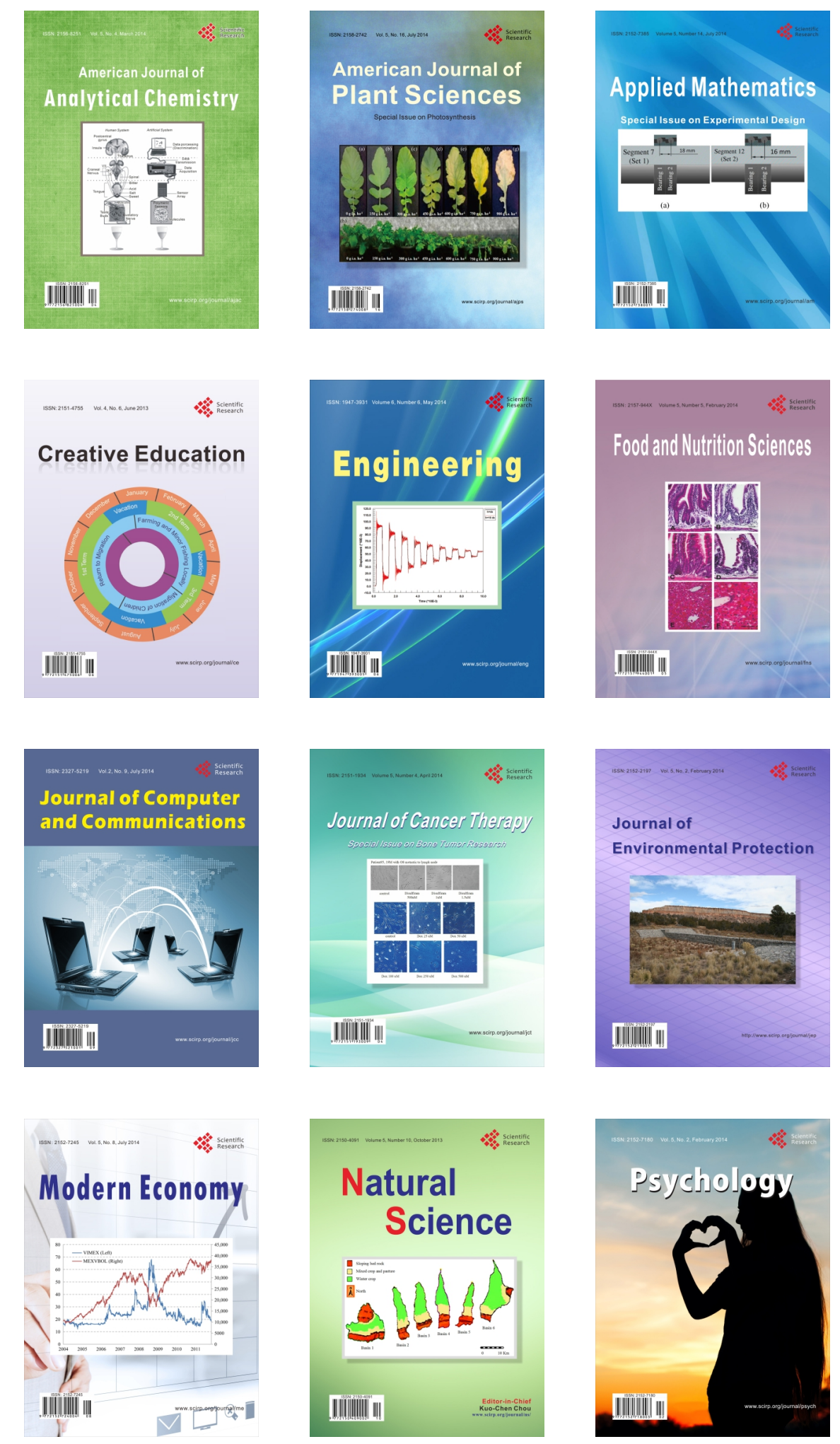